Please do not remove this page

RMIT

UNIVERSITY

\title{
Sb2Te3 and Bi2Te3 based thermopower wave sources
}

Walia, Sumeet; Weber, Rodney; Sriram, Sharath; Bhaskaran, Madhu; Latham, Kay; Zhuiykov, Serge; Kalantar Zadeh, Kourosh

https://researchrepository.rmit.edu.au/esploro/outputs/9921858263901341/filesAndLinks?institution=61RMIT_INST\&index=null

Walia, S., Weber, R., Sriram, S., Bhaskaran, M., Latham, K., Zhuiykov, S., \& Kalantar Zadeh, K. (2011). Sb2Te3 and Bi2Te3 based thermopower wave sources. Energy \& Environmental Science, 4(9), 3558-3564. https://doi.org/10.1039/c1ee01370j

Document Version: Accepted Manuscript

Published Version: https://doi.org/10.1039/c1 ee01370j

Repository homepage: https://researchrepository.rmit.edu.au (C) 2011

Downloaded On 2023/04/26 22:56:10 +1000

Please do not remove this page 
Thank you for downloading this document from the RMIT Research Repository.

The RMIT Research Repository is an open access database showcasing the research outputs of RMIT University researchers.

RMIT Research Repository: http://researchbank.rmit.edu.au/

\section{Citation:}

Walia, S, Weber, R, Sriram, S, Bhaskaran, M, Latham, K, Zhuiykov, S and Kalantar Zadeh, $\mathrm{K} 2011$, 'Sb2Te3 and Bi2Te3 based thermopower wave sources', Energy \& Environmental Science, vol. 4, no. 9, pp. 3558-3564.

See this record in the RMIT Research Repository at:

http://researchbank.rmit.edu.au/view/rmit:11910

Version: Accepted Manuscript

Copyright Statement: (c) 2011

Link to Published Version:

http://dx.doi.org/10.1039/c1ee01370j 


\title{
$\mathrm{Sb}_{2} \mathrm{Te}_{3}$ and $\mathrm{Bi}_{2} \mathrm{Te}_{3}$ based thermopower wave sources $\uparrow$
}

\author{
Sumeet Walia, ${ }^{* a}$ Rodney Weber, ${ }^{b}$ Sharath Sriram, ${ }^{a}$ Madhu Bhaskaran, ${ }^{a}$ Kay Latham, ${ }^{c}$ \\ Serge Zhuiykov, ${ }^{d}$ and Kourosh Kalantar-zadeh ${ }^{a}$
}

\author{
Received (in XXX, XXX) Xth XXXXXXXXX 200X, Accepted Xth XXXXXXXXX 200X \\ ${ }_{5}$ First published on the web $X$ th $X X X X X X X X X 200 X$ \\ DOI: 10.1039/b000000x
}

Exothermic chemical reactions from nitrocellulose are coupled onto $\mathrm{Sb}_{2} \mathrm{Te}_{3}$ (antimony telluride) and $\mathrm{Bi}_{2} \mathrm{Te}_{3}$ (bismuth telluride) layers to generate self propagating oscillating thermopower waves. P-type $\mathrm{Sb}_{2} \mathrm{Te}_{3}$ and N-type $\mathrm{Bi}_{2} \mathrm{Te}_{3}$ are employed due to their large Seebeck coefficients, high 10 electrical conductivities and their complementary semiconducting properties. Sources based on both materials exhibit high power to mass ratios: up to $0.6 \mathrm{~kW} \mathrm{~kg}^{-1}$ for $\mathrm{Sb}_{2} \mathrm{Te}_{3}$ and $1.0 \mathrm{~kW} \mathrm{~kg}^{-1}$ for $\mathrm{Bi}_{2} \mathrm{Te}_{3}$. Having both $\mathrm{P}$ - and $\mathrm{N}$-type semiconductors in the system, the combination of the outputs can be used for generating sources with polarities alternating in time.

\section{Introduction}

15 The miniaturization of power sources, while maintaining a high specific power (also called power-to-weight ratio), is necessary for applications in advanced micro/nanoscale intelligent electronics, telecommunications systems, as well as implantable bio-devices.(1-3) Integrated miniaturised 20 microsystems such as micro-electro-mechanical systems (MEMS) will struggle to attain their potential until power sources driving these systems match their dimensional scale and deliver the required power density.(4) Miniaturization is also desirable for ignition systems of heat engines, where a 25 large power surge is required solely at the start, and not over the course of operation of the engine; thereby, eliminating the need for accommodating bulky and heavy batteries for the entire journey.(5) It is known that the deployment of hybrid cars with ultimate efficiency has been held back by the lack of 30 suitable sized and high specific power batteries, with small volume and weight.(6) Although there have been recent advances in fabricating 3-D Li-ion micro/nano batteries, their specific power and energy densities are still low $\left(\sim 0.3 \mathrm{~kW} \mathrm{~kg}^{-1}\right.$ and $0.4 \mathrm{kWh} \mathrm{kg}^{-1}$, respectively).(7-8)

35 A reduction in size gives rise to problems such as ionic flow disruption around electrodes as well as electrical shorts that hamper their ability to perform effectively.(4, 9-10) Additionally, microlithography processes have proved cumbersome and expensive to transfer to batteries.(11)

$40 \quad$ Energy can also be released via systems such as fuel cells; however, they generally require large volumes and expensive electronics while exhibiting low specific powers.(12-14) Additionally, conventional batteries and fuel cells are only capable of producing direct current (DC) power, while 45 oscillatory, alternating current (AC) sources are desirable for most electrical applications

Energy can also be stored and released at high rates using technologies such as supercapacitors. They exhibit a specific power of at least $10 \mathrm{~kW} \mathrm{~kg}^{-1}$.(15-17) The major disadvantage 50 of supercapacitors is their high self-discharge rate. This renders them impractical for long-term energy storage as they have to be charged frequently in order to maintain the stored energy. Thus, none of the aforementioned technologies have so far enabled reliable miniaturized power sources with high 55 specific power.

Choi et al.(18-19) have recently demonstrated that chemically driven 'thermopower waves' guided by multiwalled carbon nanotubes (MWNT) are capable of producing specific powers as large as $7 \mathrm{~kW} \mathrm{~kg}^{-1}$. In such thermopower ${ }_{60}$ devices the highly conductive MWNT core allows the axial transportation of free electrons, that are generated via a large temperature gradient across the device. This temperature gradient is produced as a result of an exothermic reaction of a highly reactive solid fuel covering the MWNTs. In these ${ }_{65}$ systems, the high thermal conductivity of MWNTs guarantees the continuation of the reaction and the propagation of thermopower waves. The main limitation of the work was the low voltage generated, which averaged $30-50 \mathrm{mV}$ with a maximum reported voltage of $210 \mathrm{mV}$ for masses in the range 70 of just a few milligrams. The amplitude of oscillations was also low (20-30 $\mathrm{mV}$ generally). The reason for this limitation is that MWNTs exhibit a relatively low Seebeck coefficient $\left(80 \mu \mathrm{V} \mathrm{K}^{-1}\right)$.(20) In order to increase the output voltage, thermoelectric materials such as antimony telluride $\left(\mathrm{Sb}_{2} \mathrm{Te}_{3}\right)$ 75 and bismuth telluride $\left(\mathrm{Bi}_{2} \mathrm{Te}_{3}\right)$ with large respective Seebeck coefficients of 287 and $243 \mu \mathrm{V} \mathrm{K}^{-1}$ can potentially replace MWNTs.(21-24) One of the main requirements of a thermopower source core material is its high electrical conductivity. A higher electrical conductivity can increase the 80 power output as it results in larger currents.(25) This means that materials such as silicon $(\mathrm{Si})$, even in its highly-doped state, with a large Seebeck coefficient $\left(\sim 1500 \mu \mathrm{V} \mathrm{K}^{-1}\right)$ are rendered inefficient due to their low electrical conductivity.(26) $\mathrm{Sb}_{2} \mathrm{Te}_{3}$ and $\mathrm{Bi}_{2} \mathrm{Te}_{3}$, on the other hand, both 85 have high electrical conductivities. The electrical conductivity of $\mathrm{Bi}_{2} \mathrm{Te}_{3}$ is of the order of $10^{5} \mathrm{~S} \mathrm{~m}^{-1}$, while $\mathrm{Sb}_{2} \mathrm{Te}_{3}$ exhibits an electrical conductivity in the range of $0.5-1.0 \times 10^{4} \mathrm{~S} \mathrm{~m}^{-1}$ [See $\mathrm{ESI} \uparrow$ for details].(27-29)

High thermal conductivity is also required for sustaining 90 the propagation of the thermopower waves. The thermal conductivity of $\mathrm{Sb}_{2} \mathrm{Te}_{3}$ and $\mathrm{Bi}_{2} \mathrm{Te}_{3}$ is low (2.5 and $1.0 \mathrm{Wm}^{-1} \mathrm{~K}^{-1}$, respectively).(30-32) To compensate for this and to achieve the desired effective thermal conductivity, we can place the materials on highly thermally conductive 
substrates (for instance $\mathrm{Al}_{2} \mathrm{O}_{3}$ with thermal conductivity of $\left.20 \mathrm{~W} \mathrm{~m}^{-1} \mathrm{~K}^{-1}\right) .(33)$

We have recently demonstrated thermopower wave generation by coupling exothermic chemical reaction of 5 nitrocellulose to $\mathrm{Bi}_{2} \mathrm{Te}_{3}$ films supported by either a highly thermally conductive alumina $\left(\mathrm{Al}_{2} \mathrm{O}_{3}\right)$ substrate in comparison to a much less thermally conductive terracotta (baked natural polysilicate) substrate.(34) These devices produced a high specific power of the order of $1 \mathrm{~kW} \mathrm{~kg}^{-1}$ and generated 10 voltages of the order of $100-150 \mathrm{mV}$ with large oscillation amplitudes in the range of $50-140 \mathrm{mV}$. The generated voltage and the amplitude of oscillations for $\mathrm{Bi}_{2} \mathrm{Te}_{3}$-based devices were significantly larger than MWNT-based thermopower devices.

15 In this work, we use $\mathrm{Sb}_{2} \mathrm{Te}_{3}$ as the complementary thermoelectric material and compare its performance to previously demonstrated $\mathrm{Bi}_{2} \mathrm{Te}_{3}$-based thermopower devices.(34) $\mathrm{Sb}_{2} \mathrm{Te}_{3}$ is a P-type semiconductor and $\mathrm{Bi}_{2} \mathrm{Te}_{3}$ is N-type.(35-36) Such a contrast ensures that the voltage output 20 from these thermopower wave sources, with identical characteristics (one based on $\mathrm{Bi}_{2} \mathrm{Te}_{3}$ and the other based on $\mathrm{Sb}_{2} \mathrm{Te}_{3}$ ), produce both positive and negative polarities. The combination of these two can result in an alternating signal, which is required for practical applications. Similar to our 25 previous work (34), we use $\mathrm{Al}_{2} \mathrm{O}_{3}$ and terracotta as the substrates in our investigations. They are chosen due to their contrasting thermal conductivities, which will help observing the effect of thermal properties of the system on the thermopower wave propagation. A detailed comparison of ${ }_{30} \mathrm{Sb}_{2} \mathrm{Te}_{3}-$ and $\mathrm{Bi}_{2} \mathrm{Te}_{3}$-based thermopower wave devices is presented in this work.

\section{Experimental}

\subsection{Deposition of $\mathrm{Sb}_{2} \mathrm{Te}_{3}$ and $\mathrm{Bi}_{2} \mathrm{Te}_{3}$ films}

${ }_{35} \mathrm{The} \mathrm{Sb}_{2} \mathrm{Te}_{3}$ and $\mathrm{Bi}_{2} \mathrm{Te}_{3}$ films were deposited on $\mathrm{Al}_{2} \mathrm{O}_{3}$ and terracotta substrates using RF magnetron sputtering, under identical deposition conditions. High purity (99\%) $\mathrm{Sb}_{2} \mathrm{Te}_{3}$ and $\mathrm{Bi}_{2} \mathrm{Te}_{3}$ targets (Vin Karola Instruments) were used for sputtering. The chamber was pumped down to a pressure of ${ }_{40} 2 \times 10^{-5}$ Torr before starting the sputtering process. $\mathrm{Al}_{2} \mathrm{O}_{3}$ and terracotta substrates with linear dimensions of 12-15 mm $(L) \times 4-6 \mathrm{~mm}(W) \times 100 \mu \mathrm{m}(H)$ were utilised after being cleaned using acetone, isopropyl alcohol, and distilled water. The substrates were held at a constant temperature of

${ }_{45} 100{ }^{\circ} \mathrm{C}$ throughout the sputtering process, in which a power of $100 \mathrm{~W}$ and an argon atmosphere with 10 mTorr process pressure were used. Sputtering time of 90 mins resulted in a $6 \mu \mathrm{m}$ thick $\mathrm{Sb}_{2} \mathrm{Te}_{3}$ and $5 \mu \mathrm{m} \quad \mathrm{Bi}_{2} \mathrm{Te}_{3}$ films, repectively. Electrical contacts between the copper tape electrodes and the ${ }_{50}$ thermoelectric layer were made using adhesive conductive silver paste (42469, Alfa Aesar). The resistance between the electrodes for $\mathrm{Sb}_{2} \mathrm{Te}_{3}$ films and $\mathrm{Bi}_{2} \mathrm{Te}_{3}$ films ranged from 6-12 $\Omega$ and 2-10 $\Omega$, respectively.(34)
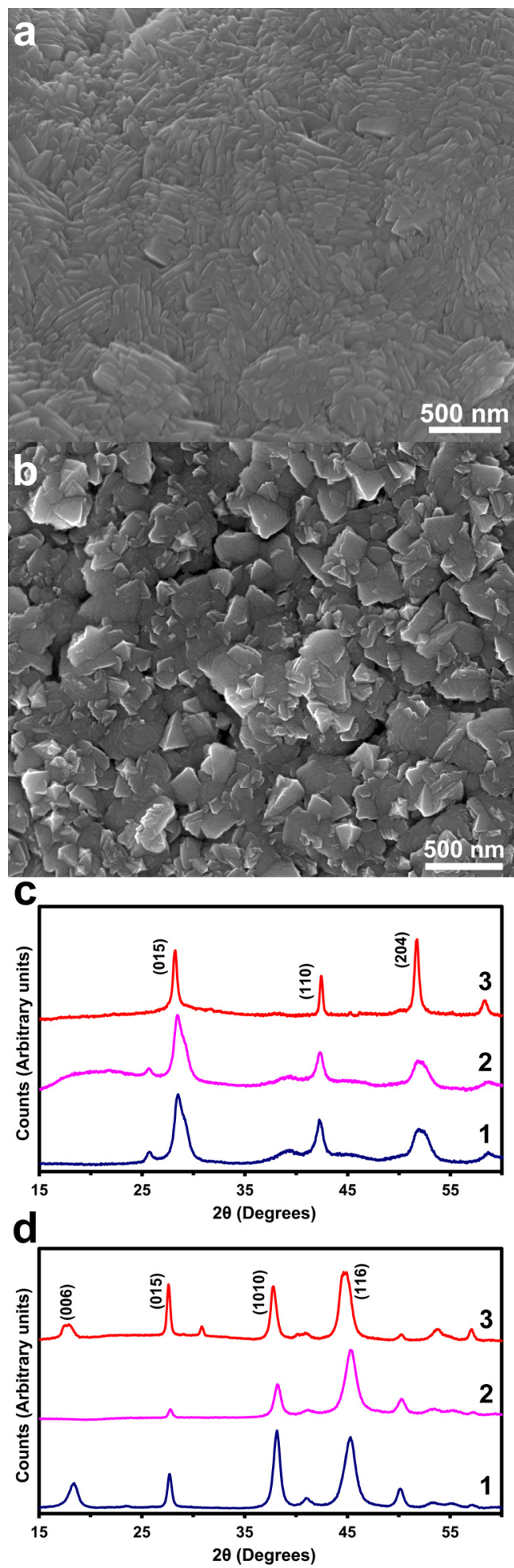

Fig 1 The SEM images of: a) $\mathrm{Sb}_{2} \mathrm{Te}_{3}$ film on $\mathrm{Al}_{2} \mathrm{O}_{3}$ b) $\mathrm{Bi}_{2} \mathrm{Te}_{3}$ film on $\mathrm{Al}_{2} \mathrm{O}_{3}$. c) 1. The XRD pattern of $\mathrm{Sb}_{2} \mathrm{Te}_{3}$ before thermopower wave propagation, 2. after adding nitrocellulose and 3. after thermopower wave propagation d) 1. The XRD pattern of $\mathrm{Bi}_{2} \mathrm{Te}_{3}$ 60 before thermopower wave propagation, 2 . after adding nitrocellulose and 3. after thermopower wave propagation.

\subsection{Preparation of fuel}

The fuel used for the exothermic reaction was a combination of nitrocellulose $\left(\mathrm{C}_{6} \mathrm{H}_{8}\left(\mathrm{NO}_{2}\right)_{2} \mathrm{O}_{5}\right)$ and sodium azide $\left(\mathrm{NaN}_{3}\right)$. 
Nitrocellulose was used due to its large enthalpy of reaction $\left(4.75 \times 10^{6} \mathrm{~J} \mathrm{~kg}^{-1}\right)$. It was prepared by dissolving millipore nitrocellulose membranes (N8645, Sigma Aldrich) in acetonitrile $(15 \mathrm{~g} / \mathrm{L})$. This solution was then dropcast on the ${ }_{5} \mathrm{Bi}_{2} \mathrm{Te}_{3}$ and $\mathrm{Sb}_{2} \mathrm{Te}_{3}$ films using a pipette and left to dry. The acetonitrile evaporated leaving an adhesive and solid nitrocellulose layer deposited on top of the thermoelectric materials. $\mathrm{NaN}_{3}$ was used to serve as a primary igniter due to its low activation energy $\left(40 \mathrm{~kJ} \mathrm{~mol}^{-1}\right.$ for $\mathrm{NaN}_{3}$, compared to $10110-150 \mathrm{~kJ} \mathrm{~mol}^{-1}$ for nitrocellulose). (37-38) $\mathrm{NaN}_{3}$ (14314, Alfa Aesar) in aqueous solution $\left(50 \mathrm{mg} \mathrm{mL}^{-1}\right)$ was then added on top of the nitrocellulose layer using a pipette. The total thickness of the fuel layer was $\sim 240 \mu \mathrm{m}$.

\section{2.3 Characterization of films}

Figures 1(a,b) show scanning electron micrographs (SEM) of $\mathrm{Sb}_{2} \mathrm{Te}_{3}$ and $\mathrm{Bi}_{2} \mathrm{Te}_{3}$ films, respectively. The images clearly show the difference between the structures of the two films with $\mathrm{Bi}_{2} \mathrm{Te}_{3}$ exhibiting a more irregular structure compared to ${ }_{20} \mathrm{Sb}_{2} \mathrm{Te}_{3}$. This confirms the polycrystalline nature of $\mathrm{Bi}_{2} \mathrm{Te}_{3}$.(34) The SEM images also show that $\mathrm{Bi}_{2} \mathrm{Te}_{3}$ films are more porous than $\mathrm{Sb}_{2} \mathrm{Te}_{3}$, when deposited on $\mathrm{Al}_{2} \mathrm{O}_{3}$ substrates under identical conditions.

A surface profilometer (Ambios Technology XP-2) was ${ }_{25}$ used to further investigate the morphology of the $\mathrm{Sb}_{2} \mathrm{Te}_{3}$ and $\mathrm{Bi}_{2} \mathrm{Te}_{3}$ surfaces and that of the substrate [see ESI $\dagger$, Figs. S1(a,b)]. The average surface roughness of $\mathrm{Sb}_{2} \mathrm{Te}_{3}$ and $\mathrm{Bi}_{2} \mathrm{Te}_{3}$ was determined to be 0.4 and $0.7 \mu \mathrm{m}$, respectively. This indicates that the $\mathrm{Bi}_{2} \mathrm{Te}_{3}$ films are more porous; thereby, 30 confirming the earlier observation made from the micrograph in Fig. 1(b). A greater porosity enables more fuel to be placed on the surface of the films. Additionally, a higher porosity is also important to facilitate increased thermal conduction between the fuel and thermoelectric films,(34) resulting in a 35 more sustained reaction propagation.

$\mathrm{X}$-ray diffraction (XRD) measurements were carried out on the $\mathrm{Sb}_{2} \mathrm{Te}_{3}$ and $\mathrm{Bi}_{2} \mathrm{Te}_{3}$ samples in order to assess the crystallinity of the films. The XRD was conducted using a Bruker D8 DISCOVER microdiffractometer fitted with a ${ }_{40}$ GADDS (General Area Detector Diffraction System). The XRD pattern for $\mathrm{Sb}_{2} \mathrm{Te}_{3}$ [Fig. 1(c),1] shows three well defined peaks, which indicate its crystalline structure. In case of $\mathrm{Bi}_{2} \mathrm{Te}_{3}$, the XRD pattern reveals a more polycrystalline structure [Fig. 1(d), 1].(39) On addition of nitrocellulose ${ }_{45}$ different effects on the XRD patterns of $\mathrm{Sb}_{2} \mathrm{Te}_{3}$ and $\mathrm{Bi}_{2} \mathrm{Te}_{3}$ are observed [Fig. 1(c), 2 and Fig. 1(d), 2]. For $\mathrm{Bi}_{2} \mathrm{Te}_{3}$ the peak at $18.1^{\circ} 2 \theta(006)$ plane for rhombohedral $\mathrm{Bi}_{2} \mathrm{Te}_{3}-$ ICDD No. [1-75-0921]) is no longer exhibited in the samples with nitrocellulose [Fig. 1(d), 1]. Possibly incoherent scattering 50 and adsorption effects may be responsible for the disappearance of this peak. It is also probable that the nitrocellulose coating on both the $\mathrm{Sb}_{2} \mathrm{Te}_{3}$ and $\mathrm{Bi}_{2} \mathrm{Te}_{3}$ samples effectively masks the surface, thus inhibiting the penetration of X-rays to, and collection of scattering data from this

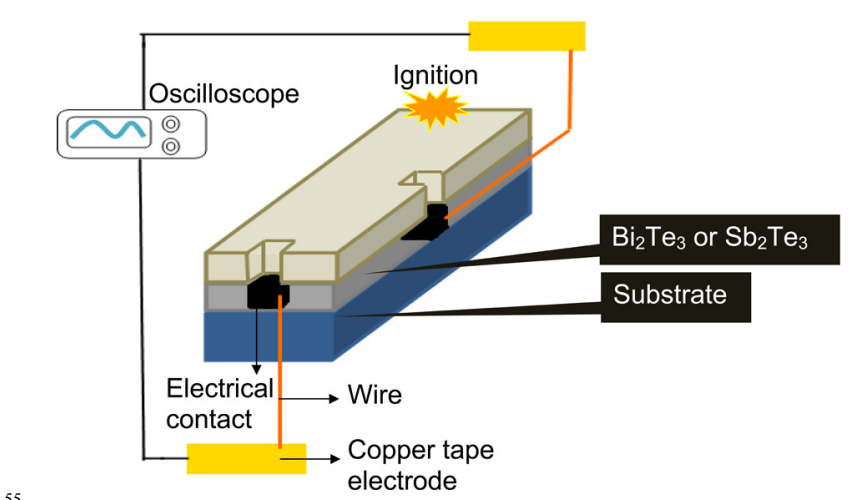

Fig 2 Schematic of the fuel/thermoelectric material/substrate thermopower wave generation system. Ignition at one end of the fuel (combination of nitrocellulose and sodium azide) layer results in a self propagating exothermic reaction. (Not to scale.)

particular peak. This effect is particularly acute for the relatively low intensity (006) $\mathrm{Bi}_{2} \mathrm{Te}_{3}$ peak, which lies in the same region as the principal XRD reflections for nitrocellulose (ICDD No. [03-0114]).(34) $\mathrm{Sb}_{2} \mathrm{Te}_{3}$ on the other ${ }_{65}$ hand does not show any significant diffraction peaks in this region. Thus, the masking effect caused by the nitrocellulose layer only results in a general decrease in diffraction intensity across its entire diffraction pattern. The XRD patterns of the samples following consumption of the nitrocellulose are also 70 shown [Fig. 1(c), 3 and Fig. 1(d), 3], and will be discussed later.

\section{Results and Discussion}

Figure 2 shows the schematic of the set-up [also see ESI†, Fig. S2 for the actual apparatus] used for the thermopower 75 experiments. Ignition takes place at one end of this system and the reaction self propagates to the other end. A custommade blow torch with a localized flame tip is used to initiate the reaction. Samples with low mass of nitrocellulose or $\mathrm{NaN}_{3}$ (masses below $15 \mathrm{mg}$ per $75 \mathrm{~mm}^{2}$ ) showed no sustained 80 wavefront propagation in any direction. Several samples using different mass of the fuels were prepared and tested. For both $\mathrm{Bi}_{2} \mathrm{Te}_{3}$ and $\mathrm{Sb}_{2} \mathrm{Te}_{3}$ systems identical masses were used to ensure statistical comparison. Ignition at one end of the system, shown in Fig. 2, results in an accelerated self ${ }_{85}$ propagating reaction wave that drives a simultaneous wave of free carriers. This wave of carriers results in a flow of current and voltage across the devices. The voltage signal exhibited a positive polarity for waves initiating at the positive electrode for P-type $\mathrm{Sb}_{2} \mathrm{Te}_{3}$ and the opposite polarity for the N-type ${ }_{90} \mathrm{Bi}_{2} \mathrm{Te}_{3}$. The duration of the output signal corresponds to the reaction time, thus enabling us to calculate the reaction propagation velocity. Even in oscillatory mode, the thermopower waves always exhibit a constant polarity during the reaction, depending on the direction of wavefront ${ }_{95}$ propagation. This suggests that the wave passes through the system faster than the cooling time of its posterior region.(18, 34) 

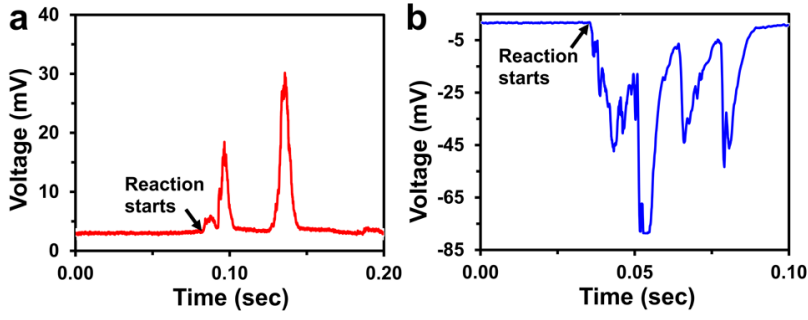

Fig 3 Comparison of oscillations between $\mathrm{Sb}_{2} \mathrm{Te}_{3}$ and $\mathrm{Bi}_{2} \mathrm{Te}_{3}$ based thermopower devices. a) Oscillatory thermopower voltage signal for $\mathrm{Sb}_{2} \mathrm{Te}_{3}$ device using $\mathrm{Al}_{2} \mathrm{O}_{3}$ substrate.b) Oscillatory thermopower 5 voltage signal for $\mathrm{Bi}_{2} \mathrm{Te}_{3}$ device using $\mathrm{Al}_{2} \mathrm{O}_{3}$ substrate. We can see that $\mathrm{Bi}_{2} \mathrm{Te}_{3}$ based devices exhibit amplitudes approximately 3 times larger than that of $\mathrm{Sb}_{2} \mathrm{Te}_{3}$ based devices. The difference is simila to the variation in the thermal conductivities of $\mathrm{Bi}_{2} \mathrm{Te}_{3}$ and $\mathrm{Sb}_{2} \mathrm{Te}_{3}$.

\subsection{Comparison of $\mathrm{Sb}_{2} \mathrm{Te}_{3}$ - and $\mathrm{Bi}_{2} \mathrm{Te}_{3}$-based thermopower} 10 devices

\section{Thermopower devices based on $\mathrm{Al}_{2} \mathrm{O}_{3}$ substrate}

The thermal conductivity of $\mathrm{Al}_{2} \mathrm{O}_{3}$ is much higher than $\mathrm{Bi}_{2} \mathrm{Te}_{3}$ and $\mathrm{Sb}_{2} \mathrm{Te}_{3}$. Both $\mathrm{Bi}_{2} \mathrm{Te}_{3}$ and $\mathrm{Sb}_{2} \mathrm{Te}_{3}$ films are comparatively thin $\left(<10 \mu \mathrm{m}\right.$ compared to the $\sim 100 \mu \mathrm{m}$ thick $\mathrm{Al}_{2} \mathrm{O}_{3}$ substrate 15 - see ESI†for further information). Thus we can assume that the $\mathrm{Al}_{2} \mathrm{O}_{3}$ substrate will dominate the thermal conduction process.(34)

Figures $3(\mathrm{a}, \mathrm{b})$ show typical voltage measurements across the fuel $/ \mathrm{Sb}_{2} \mathrm{Te}_{3} / \mathrm{Al}_{2} \mathrm{O}_{3}$ and the fuel $/ \mathrm{Bi}_{2} \mathrm{Te}_{3} / \mathrm{Al}_{2} \mathrm{O}_{3}$ systems, 20 respectively. The voltage profiles of Figs $3(\mathrm{a}, \mathrm{b})$ can be divided into an initial reaction phase followed by a cooling down phase. The reaction phase consists of a rising voltage and continues until all the combustion fuel is consumed. This is followed by a region of exponential decay.(40) The voltage 25 generated depends on the sample mass, especially the amount of fuel used (which is a combination of nitrocellulose and sodium azide). $\mathrm{Sb}_{2} \mathrm{Te}_{3}$-based devices generated voltages as large as $200 \mathrm{mV}$ with oscillations in the range of $10-40 \mathrm{mV}$. On the other hand, $\mathrm{Bi}_{2} \mathrm{Te}_{3}$ devices generated voltages as large 30 as $140 \mathrm{mV}$ with larger oscillations generally within the range of $40-140 \mathrm{mV}$. The $\mathrm{Bi}_{2} \mathrm{Te}_{3}$-based devices occasionally showed voltages as high as $300-400 \mathrm{mV}$; however, due to lack of consistency these results are not included. Figures 3(a,b) also show the difference in the oscillation amplitudes of the $\mathrm{Sb}_{2} \mathrm{Te}_{3}$ 35 and $\mathrm{Bi}_{2} \mathrm{Te}_{3}$ devices. The reason for the difference in oscillatory behaviour can be attributed to the larger thermal conductivity of $\mathrm{Sb}_{2} \mathrm{Te}_{3}$ (2.5 times that of $\mathrm{Bi}_{2} \mathrm{Te}_{3}$ ). Oscillation amplitude difference between the two devices corresponds to the difference in thermal conductivities of the two materials.

40 A larger effective thermal conductivity means that the reaction will propagate faster potentially affecting the oscillation amplitude. Previously, we have theoretically demonstrated that a change in thermal conductivity affects the rate of heat loss and hence the oscillations.(34) For 45 simplification in our theoretical analysis, we started with a one-dimensional space model and transformed it to a nondimensional system to predict the occurrence of oscillatory combustion linked to the heat losses. As a first step towards analysing the combustion, we applied the model presented by

${ }_{50}$ Mercer et al.(41) Assuming that the solid fuel combustion is exothermic, oxygen is supplied in excess, and governed by
Arrhenius kinetics with volumetric heat loss and defining the non-dimensional temperature $u$ to be:

$$
u=\frac{R T}{E}
$$

The non-dimensional equations for the conservation of heat 55 and mass are:

$$
\begin{gathered}
\frac{\partial u}{\partial t}=\frac{\partial^{2} u}{\partial x^{2}}+w e^{-1 / u}-\ell\left(u-u_{a}\right) \\
\frac{\partial w}{\partial t}=-\beta w e^{-1 / u}
\end{gathered}
$$

in which $T$ and $w$ denote the temperature and concentration of the fuel, respectively, and $x$ and $t$ are the defined space and ${ }_{60}$ time variables. We define as $\beta=\frac{{ }^{E c} p}{Q R}$, a parameter related to the properties of the fuel, and the non-dimensional volumetric heat transfer, $\ell=\frac{\mathrm{S}}{\mathrm{V}} \frac{\mathrm{hE}}{\rho \mathrm{RQA}}$ where, $\frac{\mathrm{S}}{\mathrm{V}}$ is the surface-area-to-

volume ratio of the fuel $\left(\mathrm{m}^{-1}\right)$ and and $h$ is the heat transfer coefficient from the fuel to the quiescent surroundings ${ }_{65}\left(\mathrm{~J} \mathrm{~s}^{-1} \mathrm{~m}^{-2} \mathrm{~K}^{-1}\right), \rho$ is the density of the fuel $\left(\mathrm{kg} \mathrm{m}^{-3}\right), c_{\mathrm{p}}$ is the specific heat of the fuel $\left(\mathrm{J} \mathrm{kg}^{-1} \mathrm{~K}^{-1}\right), Q$ is the heat of reaction $\left(\mathrm{J} \mathrm{kg}^{-1}\right), A$ is the pre-exponential rate constant $\left(\mathrm{s}^{-1}\right), E$ is the activation energy $\left(\mathrm{J} \mathrm{mol}^{-1}\right), R$ is the universal gas constant $\left(8.314 \mathrm{~J} \mathrm{~mol}^{-1} \mathrm{~K}^{-1}\right)$. The heat transfer coefficient $h$ is an 70 estimate for all the losses in the averaged model that we have used. For the purpose of gaining an understanding of the process, we estimated the heat losses to the substrate and the environment and lumped them together in $h$. Heat is transferred from the fuel layer to the $\left(\mathrm{Bi}_{2} \mathrm{Te}_{3}\right.$ or $\left.\mathrm{Sb}_{2} \mathrm{Te}_{3}\right)$ 75 thermoelectric/substrate layer and to the surroundings. Depending on the value of system parameters, we can predict the oscillatory behaviour of the thermopower waves. The determination of all the necessary parameter values is the key to being able to apply the model to a real system. The solution 80 of the model presented by Mercer et al., (41) assumes that the ambient temperature is absolute zero $\left(u_{a}=0\right)$. Ambient temperatures are very small relative to the reaction temperature, and hence, this inference has little effect on the overall behaviour of the solutions to this model. For the fuel, 85 the value of the parameters is as follows: $S / V=1 / 240 \mu \mathrm{m}^{-1}, \rho=$ $1600 \mathrm{~kg} \cdot \mathrm{m}^{-3}, \mathrm{c}_{\mathrm{p}}=1596 \mathrm{~J} \cdot \mathrm{kg}^{-1} \cdot \mathrm{K}^{-1}, \mathrm{Q}=4.75 \times 10^{6} \mathrm{~J} \cdot \mathrm{kg}^{-1}, \mathrm{E}=$ $1.26 \times 10^{5} \mathrm{~J} \cdot \mathrm{mol}^{-1}, \mathrm{~A}=10^{5} \mathrm{~s}^{-1}$ and $\mathrm{h}=2 \times 10^{-3} \mathrm{~J} \cdot \mathrm{s}^{-1} \cdot \mathrm{m}^{-2} \cdot \mathrm{K}^{-1}$. In all cases the $\beta$ value is 5.09 for the nitrocellulose fuel layer. The oscillation period is directly related to $\beta$ and $\ell$. For $\beta=5.09$, the 90 critical heat loss value for the onset of oscillations can be estimated as being smaller than $\ell / \beta=0.000035$ (using Fig. S3, see ESI $\uparrow$ ). The change in thermal conductivity affects the heat loss parameter. The higher thermal conductivity of $\mathrm{Sb}_{2} \mathrm{Te}_{3}$ 

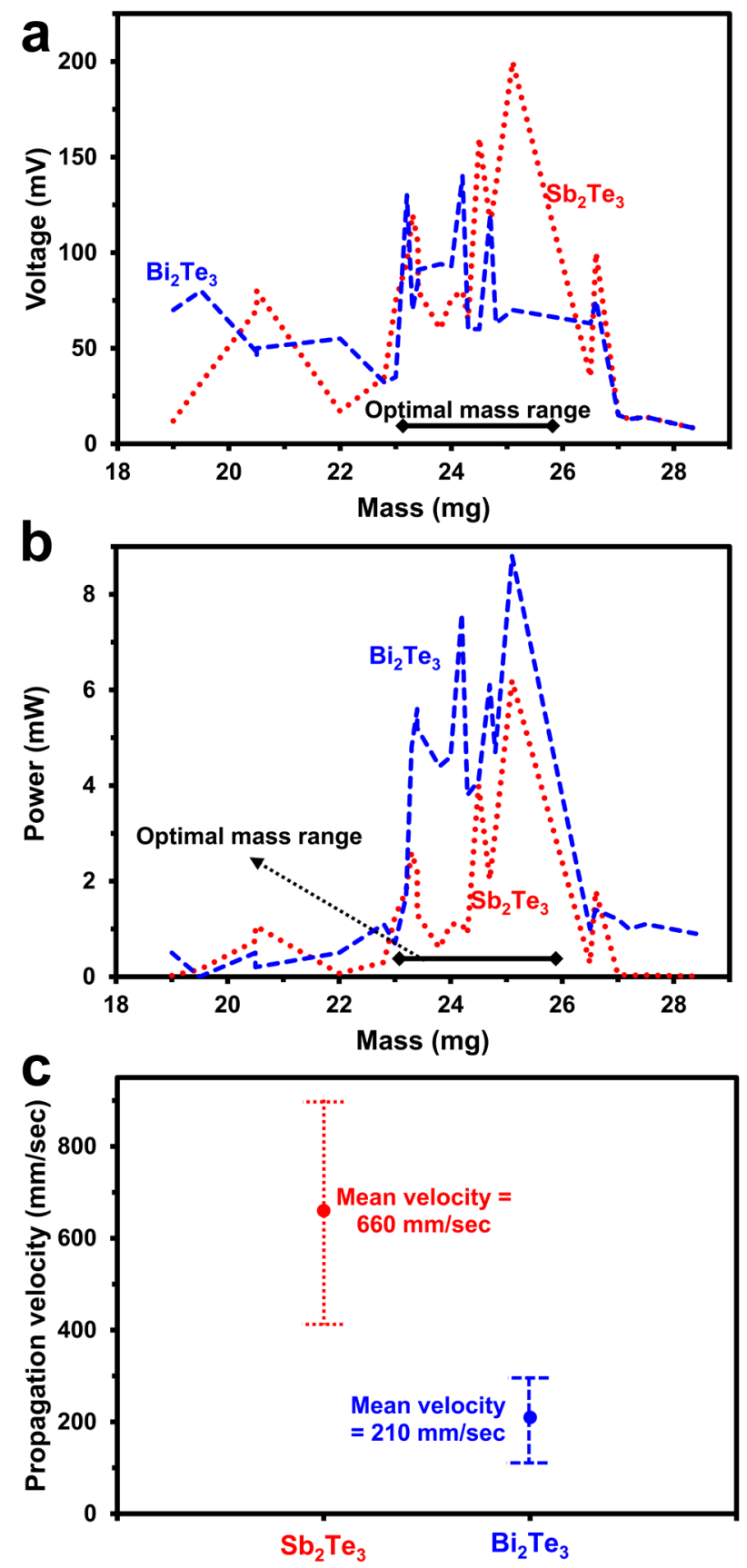

Fig 4 a) Comparison of voltage generated as a function of mass (of fuel and thermoelectric material) for $\mathrm{Sb}_{2} \mathrm{Te}_{3}$ and $\mathrm{Bi}_{2} \mathrm{Te}_{3}$ based thermopower devices. b) Power as a function of mass. c) ${ }_{5}$ Comparison of the reaction propagation velocity for $\mathrm{Sb}_{2} \mathrm{Te}_{3}$ and $\mathrm{Bi}_{2} \mathrm{Te}_{3}$ based devices.

compared to $\mathrm{Bi}_{2} \mathrm{Te}_{3}$ will enhance heat transfer (see ESI $\uparrow$, Section S5). Hence, we would predict faster combustion velocities for $\mathrm{Sb}_{2} \mathrm{Te}_{3}$-based devices and that the system would 10 be closer to the parameter values where oscillations in the combustion occur. However, as the model is based on a onedimensional average over all the layers, the resultant changes predicted are not as dramatic as observed in the experiments. Abrahamson et al. $(40,42)$ have employed a 15 similar averaged one-dimensional model. They have solved their model numerically (rather than use the asymptotic results that we have) with a set of estimated parameter values and found corresponding results to those reported in this work, albeit for carbon nanotube guided thermopower waves, which 20 are on a smaller scale than our experiments.

The analysis of voltage and power as a function of mass shows an optimal mass range for both $\mathrm{Sb}_{2} \mathrm{Te}_{3}-$ and $\mathrm{Bi}_{2} \mathrm{Te}_{3}-$ based devices. A very low amount of fuel does not generate enough heat to sustain the propagation of the exothermic 25 reaction. Too much fuel, on the other hand may provide more heat energy, but the unreacted accumulated fuel mass renders the reaction unsustainable.(34) As a result, we observed an optimal mass range $\left(22-26 \mathrm{mg}\right.$ for $\sim 75 \mathrm{~mm}^{2}$ samples) that sustained the wavefront propagation (see ESI†, Section S4.1 30 for detailed information on mass of substrates and the films).Almost both type devices exhibited well-matched trends in terms of the relation between voltage and mass [Fig. 4(a)].

Comparison of peak power vs. mass for the two different 35 materials is shown in Fig. 4(b). The peak power was determined using the equation: $P=\frac{V^{2}}{R}$ in which $P$ is the peak power in watts, $V$ is the peak output voltage in volts and $R$ the resistance in $\Omega$.

The resistance of the $\mathrm{Sb}_{2} \mathrm{Te}_{3}$ films ranged from 6-12 $\Omega$, while ${ }_{40} \mathrm{Bi}_{2} \mathrm{Te}_{3}$ films resistances were between 2-10 $\Omega$. The difference between the resistances can be attributed to the larger electrical conductivity of $\mathrm{Bi}_{2} \mathrm{Te}_{3}$ (see ESI $\dagger$,Section S6). Hence, we expect the power output from $\mathrm{Bi}_{2} \mathrm{Te}_{3}$-based devices to be higher. Experimental observations show that the peak power ${ }_{45}$ generated by $\mathrm{Sb}_{2} \mathrm{Te}_{3}$-based devices is $\sim 6 \mathrm{~mW}$, while $\mathrm{Bi}_{2} \mathrm{Te}_{3}-$ based devices on an average generate $67 \%$ larger power with the peak value of $\sim 10 \mathrm{~mW}$. The peak specific powers of the $\mathrm{Sb}_{2} \mathrm{Te}_{3}$ and $\mathrm{Bi}_{2} \mathrm{Te}_{3}$ devices were $0.6 \mathrm{~kW} \mathrm{~kg}^{-1}$ and $1.0 \mathrm{~kW} \mathrm{~kg}^{-1}$, respectively. This difference can be mainly attributed to the ${ }_{50}$ higher electrical conductivity of $\mathrm{Bi}_{2} \mathrm{Te}_{3}$. The resistance of the thermoelectric films remains almost the same even after the end of the reactions. The resistance dependence on temperature is defined by the following equation:

$$
R(T)=R_{o}\left[1+\alpha\left(T-T_{o}\right)\right]
$$

where $T$ is the temperature, $T_{0}$ is the reference temperature, $R_{o}$ ${ }_{55}$ is the resistance at $T_{o}$ and $\alpha$ is the temperature coefficient of resistivity of the material. Since, $\mathrm{Sb}_{2} \mathrm{Te}_{3}$ and $\mathrm{Bi}_{2} \mathrm{Te}_{3}$ are semiconductors they exhibit negative temperature coefficient of resistivity. (43-44) Hence, it is expected that the resistance actually decreases during the reaction propagation in our case. 60 Additionally, the XRD pattern of the samples after the thermopower wave propagation, confirm that the structures of $\mathrm{Sb}_{2} \mathrm{Te}_{3}$ and $\mathrm{Bi}_{2} \mathrm{Te}_{3}$ remain unchanged [Fig. 1(c), 3 and Fig. 1(d), 3], as the peaks remain dominantly unaltered. The average wavefront propagation velocity for $\mathrm{Sb}_{2} \mathrm{Te}_{3}$-based ${ }_{65}$ devices was approximately $0.7 \mathrm{~m} / \mathrm{s}$ compared to $\sim 0.3 \mathrm{~m} / \mathrm{s}$ average propagation velocity for $\mathrm{Bi}_{2} \mathrm{Te}_{3}$-based devices. Propagation velocities for $\mathrm{Sb}_{2} \mathrm{Te}_{3}$-based devices were generally 2-2.5 times higher than the velocity for $\mathrm{Bi}_{2} \mathrm{Te}_{3}$-based devices [Fig. 4(c)], which nicely corresponds to the difference 

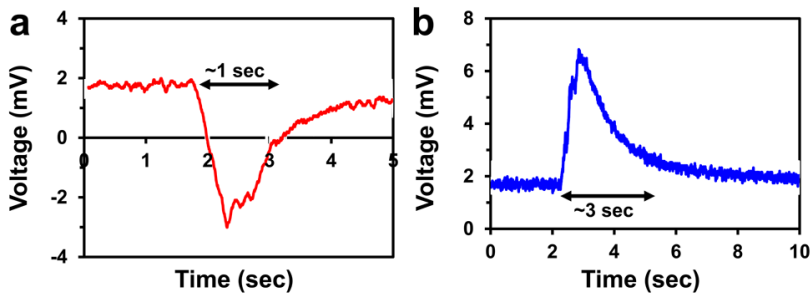

Fig 5 Comparison of thermopower voltage signals on terracotta substrates for: a) $\mathrm{Sb}_{2} \mathrm{Te}_{3}$ films, b) $\mathrm{Bi}_{2} \mathrm{Te}_{3}$ films.

in the thermal conductivities of the two thermoelectric 5 materials. A higher thermal conductivity of the thermoelectric material provides an extra path for heat conduction (i.e. the surface of the $\mathrm{Sb}_{2} \mathrm{Te}_{3}$ film) in addition to the path provided by the thermally conductive $\mathrm{Al}_{2} \mathrm{O}_{3}$ substrate. This will consequently cause the wave to travel faster on $\mathrm{Sb}_{2} \mathrm{Te}_{3}$, as the

10 thermal wave generated from the exothermic reaction travels approximately 2.5 times faster than on $\mathrm{Bi}_{2} \mathrm{Te}_{3}$ (see $\mathrm{ESI}+$ Section S5 for details).

\section{Thermopower devices based on terracotta substrate}

The oscillatory behaviour and wave front velocities strongly depend on the thermal conductivity of the substrate. Terracotta has an identical thermal conductivity to $\mathrm{Bi}_{2} \mathrm{Te}_{3}$. However, thermal conductivity of $\mathrm{Sb}_{2} \mathrm{Te}_{3}$ is 2.5 times higher. ${ }_{20}$ Consequently, we expect the rate of heat conduction for $\mathrm{Sb}_{2} \mathrm{Te}_{3}$-based devices to be approximately 2.5 times faster than $\mathrm{Bi}_{2} \mathrm{Te}_{3}$-based thermopower devices (see ESI $\uparrow$ Section S5).

Figures $5(\mathrm{a}, \mathrm{b})$ show the voltage signals obtained for ${ }_{25} \mathrm{Sb}_{2} \mathrm{Te}_{3} /$ terracotta and $\mathrm{Bi}_{2} \mathrm{Te}_{3} /$ terracotta systems, respectively. In line with our expectation, we can see that the reaction propagation for the $\mathrm{Sb}_{2} \mathrm{Te}_{3} /$ terracotta device is $\sim 3$ times faster than the $\mathrm{Bi}_{2} \mathrm{Te}_{3} /$ terracotta device. This endorses our explanation that the reaction propagation velocity depends on

30 the thermal conductivity of the material (see ESI $\dagger$ for comparison). The voltages generated by both devices are comparatively low. The reason is that a high thermal conductivity is essential for a sustained thermopower wave propagation and to maintain a high reaction temperature.(34)

35

\section{Conclusions}

This work demonstrates a performance comparison of thermopower wave systems based on two complementary thermoelectric materials, $\mathrm{Bi}_{2} \mathrm{Te}_{3}$ and $\mathrm{Sb}_{2} \mathrm{Te}_{3}$, which are $\mathrm{N}$ - and

40 P-type semiconductors, respectively. Incorporating both $\mathrm{N}$ and P-type materials resulted in output signals with opposite polarities, which is crucial for developing alternating signal sources. We have experimentally investigated the coupling of an exothermic reaction of fuel (combination of nitrocellulose

45 and sodium azide) to layers of $\mathrm{Sb}_{2} \mathrm{Te}_{3}$ and $\mathrm{Bi}_{2} \mathrm{Te}_{3}$ in order to generate output power at high rates. A highly thermally conductive substrate of $\mathrm{Al}_{2} \mathrm{O}_{3}$ accelerated the thermopower waves, which entrain free electrical carriers to produce high energy discharge rates. Our work demonstrates a new class of ${ }_{50}$ micro-power sources and shows that alternating output signals with opposite polarities can be obtained. This is an important milestone towards making efficient thermopower wave systems for future industrial applications.

\section{Notes and References}

55 Electronic supplementary information (ESI) available: Experimental measurements of thermal and electrical properties of the substrates and the thermoelectric films, additional data on calculation of specific power. See DOI:

${ }^{a}$ RMIT University, School of Electrical \& Computer Engineering, 60 Melbourne, Australia. Fax: 6139925 2007; Tel: 613 99253254; E-mail: sumeet.walia@rmit.edu.au

${ }^{b}$ University of New South Wales at Australian Defence Force Academy, School of Physical, Environmental and Mathematical Sciences, Canberra, Australia.

$6{ }^{c}$ RMIT University, School of Applied Sciences, Applied Chemistry, Melbourne, Australia.

${ }^{d}$ Commonwealth Scientific Industrial Research Organisation (CSIRO), Material Science and Engineering Division, Melbourne, Australia.

\section{References}

1. S. Kerzenmacher, J. Ducree, R. Zengerle and F.V. Stetten, Jour. of Power Sources, 2008, 182, 1.

2. G. D. Roy, S. M. Frolov, A. A. Borisov and D. W. Netzer, Progress in Energy and Combustion Science, 2004, 30, 545.

3. J. Baxter, Z. X. Bian, G. Chen, D. Danielson, M. S. Dresselhaus, A. G. Federov, T. S. Fisher, C. W. Jones, E. Maginn, U. Kortshagen, A. Manthiram, A. Nozik, D. R. Rolison, T. Sands, L. Shi, D. Sholl and Y. Y. Wu, Energy \& Environmental Science, 2009, 2, 559.

80 4. J. W. Long, B. Dunn, D. R. Rolison and H. S. White, Chemical Reviews, 2004, 104, 4463.

5. S. H. Kim, M. R. Zachariah, Advanced Materials, 2004, 16, 1821.

6. M. Armand, J. M. Tarascon, Nature, 2008, 451, 652.

7. N. J. Dudney, Journal of Material Science and Engineering B, 2005, 85 116, 245.

8. T. Djenizian, I. Hanzu, P. Knauth, Journal of Materials Chemistry, 2011.

9. S. Sekido, Solid State Ionics, 1983, 9, 777.

. 10. B. Dunn, C. J. Kim and S. Tolbert, IEEE, in MEMS 2010: 23rd IEEE

90 International Conference on Micro Electro Mechanical Systems, Technical Digest., 2010, 164.

11. D. A. Lowy, A. Patrut, Recent Patents on Nanotechnology, 2008, 2, 208.

12. O. J. Murphy, A. Cisar and E. Clarke, Electrochimica Acta, 1998, 43, 3829.

13. J. L. Martin and P. Oscnar, in Proton Exchange Membrane Fuel cells, Vol. 25 (Eds: T.Fuller, C.Hartnig,V.Ramani, H.Uchida, H.A.Gasteiger, S.Cleghorn, P.Strasser, T.Zawodzinski, D.Jones, P.Shirvanian, T.Jarvi, P.Zelenay, C.Lamy and P.Bele), The 100 Electrochemical Society, New Jersey, USA 2009, Ch. 4.

14. A. Kirubakaran, S. Jain, R. K. Nema, Renewable \& Sustainable Energy Reviews, 2009, 13, 2430.

15. H. Nakanishi and B. A. Grzybowski, Journal of Physical Chem Lett, 2010, 1, 1428.

105 16. L. L. Zhang, X. S. Zhao, Chemical Society Reviews, 2009, 38, 2520 . 
17. P. Simon, Y. Gogotsi, Nature Materials, 2008, 7, 845.

18. W. Choi, S. Hong, J. T. Abrahamson, J. H. Han, C. Song, N. Nair, S. Baik and M. S. Strano, Nat. Mater, 2010, 9, 423.

19. W. Choi, J. T. Abrahamson, J. M. Strano, M. S. Strano, Mater Today, 2010, 13, 22.

20. P. Kim, L. Shi, A. Majumdar, P. L. McEuen, Phys. Rev. Lett.,2001 87, Article No. 215502

21. M. Takashiri, M. Takiishi, S. Tanaka, K. Miyazaki and H. Tsukamoto, Journal of Appl. Phys, 2007, 101, 5.

10 22. R. Venkatasubramanian, E. Siivola, T. Colpitts and B. O'Quinn, ${ }_{65}$ Nature, 2001, 413, 597.

23. A. J. Minnich, M. S. Dresselhaus, Z. F. Ren, G. Chen, Energy \& Environmental Science, 2009, 2, 466.

24. J. J. Shen, T. J. Zhu, X. B. Zhao, S. N. Zhang, S. H. Yang and Z. Z. Yin, Energy \& Environmental Science, 2010, 3, 1519.

25. A. D. LaLonde, Y. Pei, G. J. Snyder, Energy \& Environmental Science, 2011, 4, 2090 .

26. W. Fulkerson, J. P. Moore, R. K. Williams, R. S. Graves and D. L. McElroy, Physical Rev, 1968, 167, 765.

20 27. C. B. Satterthwaite and R. W. Ure, Physical Rev, 1957, 108, 1164.

28. B. Lv, S. B. Hu, W. Li, X. Di, L. H. Feng, J. Q. Zhang, L. L. Wu, Y. P. Cai, B. Li and Z. Lei, International Journal of Photoenergy, 2010, Article No. 476589.

29. K. Wojciechowski, E. Godlewska, K. Mars, R. Mania, G. Karpinski, P. Ziolkowski, C. Stiewe and E. Müller,Vacuum, 2008, 82, 1003.

30. H. J. Goldsmid, Proceedings of the Physical Society of London Section B, 1956, 69, 203.

31. W. Wang, X. Yan, B. Poudel, Y. Ma, Q. Hao, J. Yang, G. Chen and Z. Ren, Journal of Nanoscience and Nanotechnology, 2008, 8, 452.

30 32. R. Lan, R. Endo, M. Kuwahara, Y. Kobayashi, M. Susa, Japanese Journal of Applied Physics, 2010,49, Article No. 078003.

33. M. M. Safarov and K. Madzhidov, Journal of Engineering Physics and Thermophysics, 1986, 50, 341.

34. S. Walia, R. Weber, K. Latham, P. Petersen, J. T. Abrahamson, M. S. Strano and K. Kalantar-zadeh, Advanced Functional Materials, 2011, 21, 2072.

35. I. Sommer, Journal of Crystal Growth, 1972, 12, 259

36. A. Zimmer, N. Stein, L. Johann, H. Terryn, C. Boulanger, Surface and Interface Analysis, 2008, 40, 593.

40 37. A. K. Burnham, L. E. Fried, paper presented at the 27th Aging, Compatibility and Stockpile Stewardship Conference, Los Alamos, USA, 2006.

38. K. Katoh, S. Ito, S. Kawaguchi, E. Higashi, K. Nakano, Y. Ogata and Y.Wada, Journal of Thermal Analysis and Calorimetry, 2010, 100, 303.

39. P. P. Pradyumnan, Swathikrishnan, Indian Journal of Pure \& Applied Physics, 2010, 48, 115.

40. J. T. Abrahamson, W. Choi, N. S. Schonenbach, J. Park, J-H. Han, M. P. Walsh, K. Kalantar-zadeh, and M. S. Strano, ACS Nano, $2011, \mathbf{5}, 367$.

41. G. N. Mercer, R. O. Weber, H. S. Sidhu, Proceedings of the Royal Society of London Series A-Mathematical Physical and Engineering Sciences, 1998, 454, 2015.

42. J. T. Abrahamson and M. S. Strano, Journal of Physical Chemistry
43. V. D. Das, N. Soundararajan, M. Pattabi, Journal of Materials Science, 1987, 22, 3522.

44. V. D. Das, N. Soundararajan, Physical Review B, 1988, 37, 4552. 